\title{
TITLE:
}

\section{Lithium Dendrite Growth in Glassy and Rubbery Nanostructured Block Copolymer Electrolytes}

\section{$\operatorname{AUTHOR}(S)$ :}

Schauser, Nicole S.; Harry, Katherine J.; Parkinson, Dilworth Y.; Watanabe, Hiroshi; Balsara, Nitash P.

\section{CITATION:}

Schauser, Nicole S. ... [et al]. Lithium Dendrite Growth in Glassy and Rubbery

Nanostructured Block Copolymer Electrolytes. Journal of The Electrochemical Society 2015, 162(3): A398-A405

\section{ISSUE DATE:}

2015-01

URL:

http://hdl.handle.net/2433/260846

\section{RIGHT:}

(C) The Author(s) 2014 This is an open access article distributed under the terms of the Creative Commons Attribution 4.0 License (CC BY,

http://creativecommons.org/licenses/by/4.0/), which permits unrestricted reuse of the work in any medium, provided the original work is properly cited. 
Journal of the Electrochemical Society

OPEN ACCESS

Lithium Dendrite Growth in Glassy and Rubbery Nanostructured Block Copolymer Electrolytes

To cite this article: Nicole S. Schauser et al 2015 J. Electrochem. Soc. 162 A398

View the article online for updates and enhancements. 


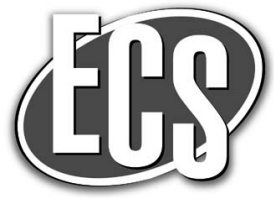

\title{
Lithium Dendrite Growth in Glassy and Rubbery Nanostructured Block Copolymer Electrolytes
}

\author{
Nicole S. Schauser, ${ }^{\mathrm{a}, \mathrm{b}}$ Katherine J. Harry, ${ }^{\mathrm{a}, \mathrm{b}, *}$ Dilworth Y. Parkinson, ${ }^{\mathrm{c}}$ Hiroshi Watanabe, ${ }^{\mathrm{d}}$ \\ and Nitash P. Balsara $\mathbf{b}^{\mathrm{b}, \mathrm{e}, \mathrm{f}, * *, \mathrm{z}}$
}

\author{
${ }^{a}$ Department of Materials Science and Engineering, University of California, Berkeley, California 94720, USA \\ ${ }^{b}$ Materials Science Division, Lawrence Berkeley National Laboratory, Berkeley, California 94720, USA \\ ${ }^{c}$ Advanced Light Source Division, Lawrence Berkeley National Laboratory, Berkeley, California 94720, USA \\ ${ }^{d}$ Institute for Chemical Research, Kyoto University, Uji, Kyoto 611-0011, Japan \\ ${ }^{e}$ Environmental Energy Technology Division, Lawrence Berkeley National Laboratory, Berkeley, \\ California 94720, USA \\ ${ }^{f}$ Department of Chemical and Biomolecular Engineering, University of California, Berkeley, California 94720, USA
}

\begin{abstract}
Enabling the use of lithium metal anodes is a critical step required to dramatically increase the energy density of rechargeable batteries. However, dendrite growth in lithium metal batteries, and a lack of fundamental understanding of the factors governing this growth, is a limiting factor preventing their adoption. Herein we present the effect of battery cycling temperature, ranging from 90 to $120^{\circ} \mathrm{C}$, on dendrite growth through a polystyrene-block-poly(ethylene oxide)-based electrolyte. This temperature range encompasses the glass transition temperature of polystyrene $\left(107^{\circ} \mathrm{C}\right)$. A slight increase in the cycling temperature of symmetric lithium-polymer-lithium cells from 90 to $105^{\circ} \mathrm{C}$ results in a factor of five decrease in the amount of charge that can be passed before short circuit. Synchrotron hard X-ray microtomography experiments reveal a shift in dendrite location from primarily within the lithium electrode at $90^{\circ} \mathrm{C}$, to primarily within the electrolyte at $105^{\circ} \mathrm{C}$. Rheological measurements show a large change in mechanical properties over this temperature window. Time-temperature superposition was used to interpret the rheological data. Dendrite growth characteristics and cell lifetimes correlate with the temperature-dependent shift factors used for time-temperature superposition. Our work represents a step toward understanding the factors that govern lithium dendrite growth in viscoelastic electrolytes.

(c) The Author(s) 2014. Published by ECS. This is an open access article distributed under the terms of the Creative Commons Attribution 4.0 License (CC BY, http://creativecommons.org/licenses/by/4.0/), which permits unrestricted reuse of the work in any medium, provided the original work is properly cited. [DOI: 10.1149/2.0511503jes] All rights reserved.
\end{abstract}

Manuscript submitted November 14, 2014; revised manuscript received December 15, 2014. Published December 29, 2014.

Energy density and safety are two parameters that drive current research for improved rechargeable lithium batteries in applications such as electric vehicles and personal electronics. ${ }^{1}$ Many groups around the world are working on innovative battery chemistries, such as lithiumsulfur $^{2-5}$ and lithium-air, ${ }^{3,6-8}$ in an effort to improve battery energy density. Virtually all approaches that affect a substantial increase of the energy density of rechargeable batteries beyond that of lithiumion batteries require the use of a lithium metal anode. ${ }^{4,9}$ Gallagher et al. show that coupling a lithium metal anode with currently available lithium cathodes results in energy densities that are three to six times larger than existing batteries used in electric vehicles. Likewise, lithium-sulfur and lithium-air chemistries rely on lithium metal anodes for improved energy density; battery energy densities obtained using a conventional graphite anode with sulfur and air cathodes are similar to those of traditional lithium ion batteries. ${ }^{10}$

The adoption of rechargeable lithium metal anode batteries has been hindered, however, by the formation of dendrites during battery cycling. ${ }^{1,11,12}$ Upon repeated stripping and deposition, lithium metal deposits unevenly on the anode, creating protrusions that grow and eventually short the cell. ${ }^{13}$ Not only is the battery then unusable, but the flammable nature of typical liquid and gel electrolytes based on alkyl carbonates can result in catastrophic failure. ${ }^{1,14}$ Uncontrolled deposition of lithium metal can also take place in a conventional lithium-ion cell with a graphitic anode if the charging rate is not properly controlled. ${ }^{15}$ Therefore, much research has focused on finding electrolytes that are stable against lithium metal anodes and on characterizing the state of lithium metal anodes during cycling. ${ }^{16-22}$

Polymer electrolytes are a nonflammable alternative to conventional liquid and gel electrolytes, and undoubtedly improve device safety. ${ }^{23,24}$ The most common polymer electrolyte studied is a mixture of lithium salts and poly(ethylene oxide) (PEO). ${ }^{24-28}$ Though PEObased electrolytes address the flammability issue of liquid electrolytes, they are still unable to prevent dendrites from growing across the electrolyte. ${ }^{29-32}$ Pioneering theoretical work of Monroe and Newman

\footnotetext{
*Electrochemical Society Student Member.

**Electrochemical Society Active Member.

${ }^{\mathrm{z}}$ E-mail: nbalsara@berkeley.edu
}

indicated that solid electrolytes with a high shear modulus would suppress dendrite growth. ${ }^{33}$ This turned attention to improving electrolyte mechanical properties. ${ }^{16,34-36}$ Unfortunately, PEO-based electrolytes are only conductive in the rubbery state. ${ }^{37}$ One method to increase the electrolyte modulus is to use block copolymers, combining PEO with a rigid polymer such as polystyrene (PS). ${ }^{38-40}$ The well-established phenomenon of microphase separation results in the formation of cocontinuous stiff PS-rich domains and rubbery PEO-rich domains. The typical widths of these domains range from ten to several hundred nanometers. ${ }^{41}$ Previous studies have shown that nanostructured electrolytes based on polystyrene- $b$-poly(ethylene oxide) (SEO) greatly improve cycle life-time compared to PEO. ${ }^{40,42}$

Significant work is being done to gain a fundamental understanding of the complex factors that govern the formation, growth, and morphological characteristics of structures formed during lithium stripping and plating. A large majority of studies were conducted in liquid electrolytes wherein protrusions of different geometries were obtained depending on factors such as current density, electrolyte viscosity, additives, etc. ${ }^{19,43-45}$ The switch to a solid polymer electrolyte resulted in a significant change in dendrite morphology; ${ }^{13}$ however, the factors governing this change were unclear due to the large number of variables that change between different electrolyte systems. This present work bridges the dendrite morphology results obtained in solid and liquid electrolytes through the use of only a single electrolyte material. By changing only the cycling temperature, we are able to observe both dendrite morphologies characteristic of solid electrolytes ${ }^{13}$ and liquid electrolytes. ${ }^{29}$ Thus, a direct connection between electrolyte modulus and dendrite morphology is revealed.

Recent X-ray microtomography experiments have shown that repeated cycling of lithium/SEO symmetric cells results in the formation of globular dendritic structures at the lithium metal/SEO interface, with much of the dendrite residing within the lithium electrode. ${ }^{13}$ The existence of these subsurface features in the lithium electrode suggested that the mechanism of dendrite nucleation and growth in block copolymers was fundamentally different from that in liquid electrolytes: numerous studies of dendrite formation in liquid and gel electrolytes have concluded that dendrites emanate from the electrode/electrolyte interface with no evidence of subsurface 
structures. ${ }^{46-49}$ The subsurface dendritic structures reported in reference 13 were obtained from cycling symmetric cells at $90^{\circ} \mathrm{C}$ - below the glass transition temperature $\left(T_{\mathrm{g}}\right)$ of the PS-rich microphase and above the $T_{\mathrm{g}}$ and melting temperature of the PEO-rich microphase. It is not clear if the difference in lithium dendrite morphology observed between SEO and liquid electrolytes is due to changes in electrolyte modulus or due to the nanostructured nature of SEO.

In this paper, we report on the effect of cycling temperature on dendrite formation in lithium-SEO-lithium cells, in an effort to improve the fundamental understanding of the factors governing dendrite growth through a single polymer electrolyte system. We cover a relatively narrow range of temperatures, from 90 to $120^{\circ} \mathrm{C}$. The morphology of the nanostructured electrolyte is insensitive to temperature changes in this regime. ${ }^{50}$ The mechanical properties of SEO, however, change dramatically over this temperature range because the $T_{\mathrm{g}}$ of the PS-rich microphase is $107^{\circ} \mathrm{C}$. The theory of Monroe and Newman ${ }^{33}$ is limited to interfaces between lithium electrodes and ideal solid electrolytes that are characterized by a constant shear modulus. On the other hand, the shear moduli of polymers are complex, i.e. they have in-phase and out-of-phase components, and depend strongly on frequency in addition to temperature. In other words, the shear modulus is not a well-defined constant but rather can vary by orders of magnitude depending on the frequency of interest. The energy required to deform polymers thus depends not only on instantaneous strain but strain history. One of the goals of this paper is to begin to address this complexity.

\section{Experimental}

Electrolyte preparation. - The relevant properties of the SEO copolymer used in this study are provided in Table I. ${ }^{41}$ This SEO was synthesized and prepared by our group as described in Singh et al. ${ }^{39}$ All sample preparation and cell assembly was carried out in an argon glove box with less than 0.1 parts per million (ppm) $\mathrm{H}_{2} \mathrm{O}$ and less than $8 \mathrm{ppm} \mathrm{O}_{2}$. A mixture of lithium bis(trifluoromethanesulfone)imide (LiTFSI) salt and SEO was used as the electrolyte. The molar ratio of lithium ions to ethylene oxide monomers, $r$, was held fixed at 0.085 . This ratio was used because it was found to maximize the conductivity of SEO electrolytes. ${ }^{51}$ The mixture was dissolved in 1methyl-2-pyrrolidone (NMP) at $90^{\circ} \mathrm{C}$ and the solution was then cast onto smooth nickel foil using a home-built casting device operated at $60^{\circ} \mathrm{C}$. The film was left on the solvent caster at $60^{\circ} \mathrm{C}$ for at least $12 \mathrm{~h}$, and then placed into an evacuated antechamber at $90^{\circ} \mathrm{C}$ for at least 12 additional $\mathrm{h}$ to remove any residual solvent. Due to natural variation on solvent casting, final film thicknesses were $27 \pm 9 \mu \mathrm{m}$. There were no discernible correlations between film thickness and the results presented in this paper.

Li-SEO-Li symmetric cell assembly. - A 0.5 inch diameter disk of electrolyte was punched from the film prepared as stated above, and sandwiched between two $150 \mu \mathrm{m}$ thick, 7/16 inch diameter disks of lithium foil (FMC Lithium). A nickel current collector tab was placed on both sides of the symmetric cell and the assembly was vacuum sealed on all sides in a polypropylene-lined aluminum pouch.

Galvanostatic cycling. - Cells were galvanostatically cycled using either a Maccor Series 4000 Battery Tester or a Biologic VMP3 potentiostat. Cells were allowed to equilibrate at the temperature of interest for an hour before cycling. Each cell was then first subjected to five conditioning cycles. During each cycle, a current density of $0.02 \mathrm{~mA} / \mathrm{cm}^{2}$ was imposed in one direction for $4 \mathrm{~h}$, followed by a $45 \mathrm{~min}$ rest period, followed by the imposition of a constant current density of $0.02 \mathrm{~mA} / \mathrm{cm}^{2}$ in the opposite direction, followed by another $45 \mathrm{~min}$ rest period. Cells were then cycled with the same time intervals at a current density of $0.175 \mathrm{~mA} / \mathrm{cm}^{2}$ until a sudden drop in the voltage required to maintain the target current density was observed. This was taken as the signature of a dendrite short. The thickness of lithium transferred between the electrodes in each half cycle at $0.175 \mathrm{~mA} / \mathrm{cm}^{2}$ was $3.13 \mu \mathrm{m}$.

Linear rheology measurements. - A neat polymer sample was prepared inside an argon glove box by adding polymer into a $0.9 \mathrm{~mm}$ thick polycarbonate spacer with an $8 \mathrm{~mm}$ diameter hole, and pressing it between two Teflon sheets in a hand press heated to $120^{\circ} \mathrm{C}$. Enough polymer was sequentially added to the spacer such that a slight bulge of polymer was seen to protrude from above the spacer. The sample was left in the press at temperature for around $4 \mathrm{~h}$, then removed from the spacer using a metal punch and placed back into the hand press between Teflon sheets for an additional $2 \mathrm{~h}$. The polycarbonate spacer was placed in the press next to the sample so that the thickness of the sample would exactly match that of the spacer. The final sample, an opaque $8 \mathrm{~mm}$ diameter disk, was transferred in a dessicator to a Rheometric Scientific ARES Rheostat. Meanwhile, the rheometer plattens were cleaned and heated to $90^{\circ} \mathrm{C}$ under nitrogen. The platten gap position was zeroed and then the sample was placed between the plattens - the sample had contact with air for less than 2 min before the oven was closed and nitrogen flow resumed. The plattens were then heated to $120^{\circ} \mathrm{C}$ and the sample was left to equilibrate for $1 \mathrm{~h}$. At each measurement temperature, a dynamic strain test was performed at a frequency of $10 \mathrm{rad} / \mathrm{s}$ to ensure measurement in the linear regime. Then a dynamic frequency test was performed at a low strain in the linear regime, chosen such that the torque applied by the instrument was always above $0.2 \mathrm{gm}-\mathrm{cm}$, which ensured accurate measurements. Thermal expansion of the metal plattens was accounted for when recording sample thickness at each temperature. Temperatures used for measurements were $120,112,105,97$ and $90^{\circ} \mathrm{C}$. Each time the temperature was changed, the sample was left to equilibrate for 30 min. A normal force between 10 and $40 \mathrm{gm}$ was applied to the sample during measurement to ensure adequate adhesion to the plattens. The experiments were repeated with a salty polymer sample $(r=0.085)$. Due to limited material, only one sample of each type was made but experiments at each temperature were repeated several times. Slight pink discoloration of the neat sample was noticed before the tests and was taken to be a sign of contamination. An attempt to scrape away most of the discoloration was fairly successful but the sample still contained some surface contamination. Final sample thicknesses were around $0.88 \mathrm{~mm}$. Good sample adhesion to the plattens was confirmed during the removal process, as significant temperature and effort were needed to separate the sample from the plattens. No significant difference in modulus between neat and salty samples was found, similar to a previous study by our group. ${ }^{39}$ This is expected if the mechanical properties of the block copolymer are governed by the PS block; the salt resides primarily in the PEO-rich microphase. Values shown in this work are averages of both samples.

Hard X-ray microtomography.- Hard X-ray microtomography imaging of our cells was performed at Beamline 8.3.2 at the Advanced Light Source at Lawrence Berkeley National Laboratory. ${ }^{52,53}$

\section{Table I. Key properties of the polystyrene-block-poly(ethylene oxide) polymer electrolyte used in this study. ${ }^{41}$}

SEO (240-269)
Publication Name
$\mathrm{M}_{\mathrm{PS}}{ }^{\mathrm{a}}(\mathrm{kg} / \mathrm{mol})$

240
$\mathrm{M}_{\mathrm{PEO}}{ }^{\mathrm{a}}(\mathrm{kg} / \mathrm{mol})$

269
$\phi_{\mathrm{EO}}^{\mathrm{b}}$

0.50

$\mathrm{PDI}^{\mathrm{b}}$

1.26

Morphology

${ }^{a} \mathrm{M}_{\mathrm{PS}} / \mathrm{M}_{\mathrm{PEO}}$ is the molecular weight of the polystyrene/poly(ethylene oxide) block, respectively.

${ }^{\mathrm{b}} \phi_{\mathrm{EO}}$ is the volume fraction of the ethylene oxide block, and PDI is the polydispersity index. 


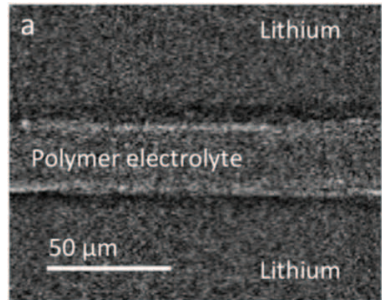

d

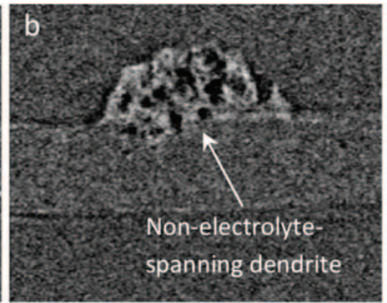

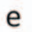

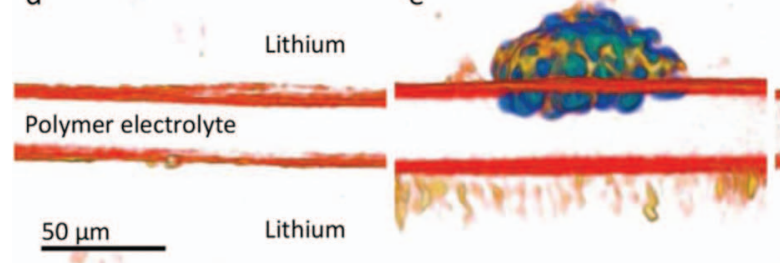

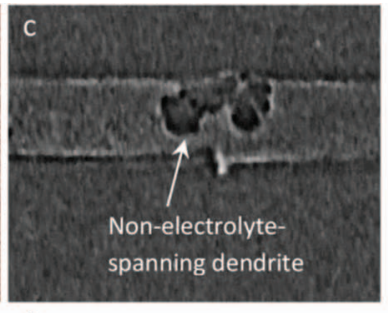

f

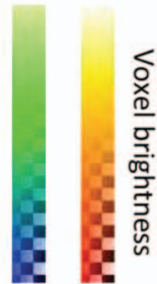

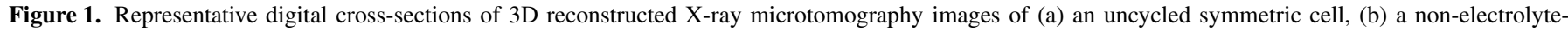

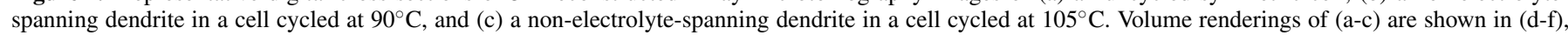

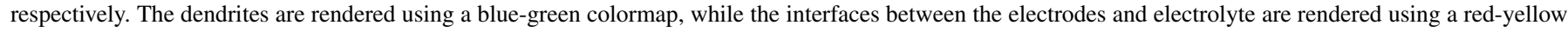
colormap. The added color bars serve as a reference for voxel brightness but do not necessarily accurately depict the relative brightness values in each image.

All of the cells studied by X-ray microtomography were first cycled until they shorted. Shorted symmetric cells were prepared for the microtomography experiments in an argon environment in a glove box. A 1/8 inch diameter punch was used to cut out the central portion of each cell, and any remaining nickel current collectors were removed. A smaller sample and removal of the highly X-ray absorbing nickel tabs leads to better image quality. The smaller sample was then vacuum sealed in a new pouch and imaged at the beamline at $4 \times$ and $10 \times$ magnifications with a beam energy of $20 \mathrm{keV}$. A total of 7 cells were imaged at $90^{\circ} \mathrm{C}, 8$ were imaged at $105^{\circ} \mathrm{C}$ and 8 were imaged at $120^{\circ} \mathrm{C}$. Thus the total electrode/electrolyte interface area imaged at each temperature was $110.8 \mathrm{~mm}^{2}, 126.7 \mathrm{~mm}^{2}$, and $126.7 \mathrm{~mm}^{2}$. The pixel size of the images was $0.00161 \mathrm{~mm}^{-2}$ and $0.000646 \mathrm{~mm}^{-2}$ for the $4 \times$ and $10 \times$ magnifications, respectively. Images were preprocessed, and tomographic reconstruction was performed with Fourier methods with the commercial Octopus software. A median filter was used to process the images prior to further analysis. Reconstructed three dimensional (3D) images were analyzed using the commercially available Avizo software package. Data acquisition and analysis builds on methods described in reference 13 .

In Figure 1a we show a digital cross-section through a reconstructed 3D X-ray microtomography image of an uncycled lithium symmetric cell used in our experiments. The image contains three distinct regions - a brighter $30 \mu \mathrm{m}$-thick polymer electrolyte sandwiched between two darker slices of lithium metal. The grayscale pixel values in the image correspond to the relative X-ray linear absorption coefficients of the material at that position - brighter pixels correspond to higher X-ray absorption at that point. Thus, the lithium electrodes appear darker than the polymer electrolyte in Figure 1a because they are more X-ray transmissive. The electrode-electrolyte interface is embellished by a thin dark band on the electrode side and a thin bright band on the electrolyte side; this is a result of Fresnel phase contrast arising during the imaging of samples containing interfaces. ${ }^{54}$ Effects of Fresnel phase contrast are also apparent within the dendrites. Within each phase, there can be real variations in pixel brightness due to variation in X-ray absorption, but a portion of the variation is also due to numerous sources of noise.

In Figure 1b we show an X-ray microtomography cross-sectional image of a cell cycled at $90^{\circ} \mathrm{C}$. The dendritic structure obtained in the presence of our SEO electrolyte is composed of globular clusters, which is distinct from mossy or needle-like dendrites seen on lithium electrodes cycled in conventional electrolytes. ${ }^{29,49,55}$ For simplicity, we refer to structures formed at the electrode-electrolyte interface due to cell cycling as dendrites. Consistent with data presented in reference 13, the dendritic structure shown in Figure $1 \mathrm{~b}$ is a composite, comprising both lithium and polymer, and it resides predominantly within one of the lithium electrodes. We note that the brightness variations within and around the dendrite arise in part due to phase contrast effects between the lithium and electrolyte described previously, but could also arise from the existence of compounds with greater Xray absorption coefficients. For example, because LiTFSI salt has a higher X-ray absorption coefficient than the SEO copolymer, brighter regions in the image could indicate higher concentrations of LiTFSI salt. The image features enable differentiation of the dendritic structure from either the electrode or electrolyte phases. In Figure 1c, we show a typical dendritic structure formed when the cell is cycled at $105^{\circ} \mathrm{C}$. This dendritic structure is more uniform than that in Figure $1 \mathrm{~b}$; it is evident that the dendritic structure formed at $105^{\circ} \mathrm{C}$ is composed of larger lithium substructures than occur in dendrites observed at $90^{\circ} \mathrm{C}$. In addition, most of the dendritic structure obtained while cycling at $105^{\circ} \mathrm{C}$ resides within the electrolyte. There are thus qualitative differences in the dendritic structures formed at 90 and $105^{\circ} \mathrm{C}$. In a given cell, dendrites were observed to grow from both electrodes roughly equally; for simplicity the images in Figure 1 are oriented so the dendrites originate from the top electrode. Due to image editing, the pixels depict relative, not absolute, absorption values. This accounts for the slight brightness variations seen between Figures 1a, 1b and $1 \mathrm{c}$.

Stacks of slices of the type shown in Figures 1a-1c were combined into volumes to generate $3 \mathrm{D}$ visualizations of the sample volumes of interest, shown in Figures 1d-1f. The visualizations in these figures, known as volume renderings, are based on a colormap which maps pixel values in the 3D volume array onto both color and opacity values. The dendritic structures were digitally labeled, or "segmented," by manually selecting their area on a subset of slices through the volume and then interpolating to fill in the remaining areas. The bright regions within the dendritic structures (see Figure 1b) were assumed to represent the electrolyte and hence were not selected as part of the lithium dendrite. For the dendrite volume renderings in Figures 1d-1f, lower pixel brightness values are mapped to blue and transparent and higher pixel values to green and opaque. The regions outside the dendrite were rendered using a separate red-yellow colormap. Using these two colormaps facilitates the identification of the electrode-electrolyte interfaces. Thus in the figures, only the dendrite and the electrode-electrolyte interfaces are rendered, allowing clear visualization of the large difference in dendrite volume located in the lithium electrode; compare Figures 1d and 1e. After dendrite segmentation, the dendrite volume can be determined by counting the number of voxels (3D pixels) that have been labeled as dendrite. 

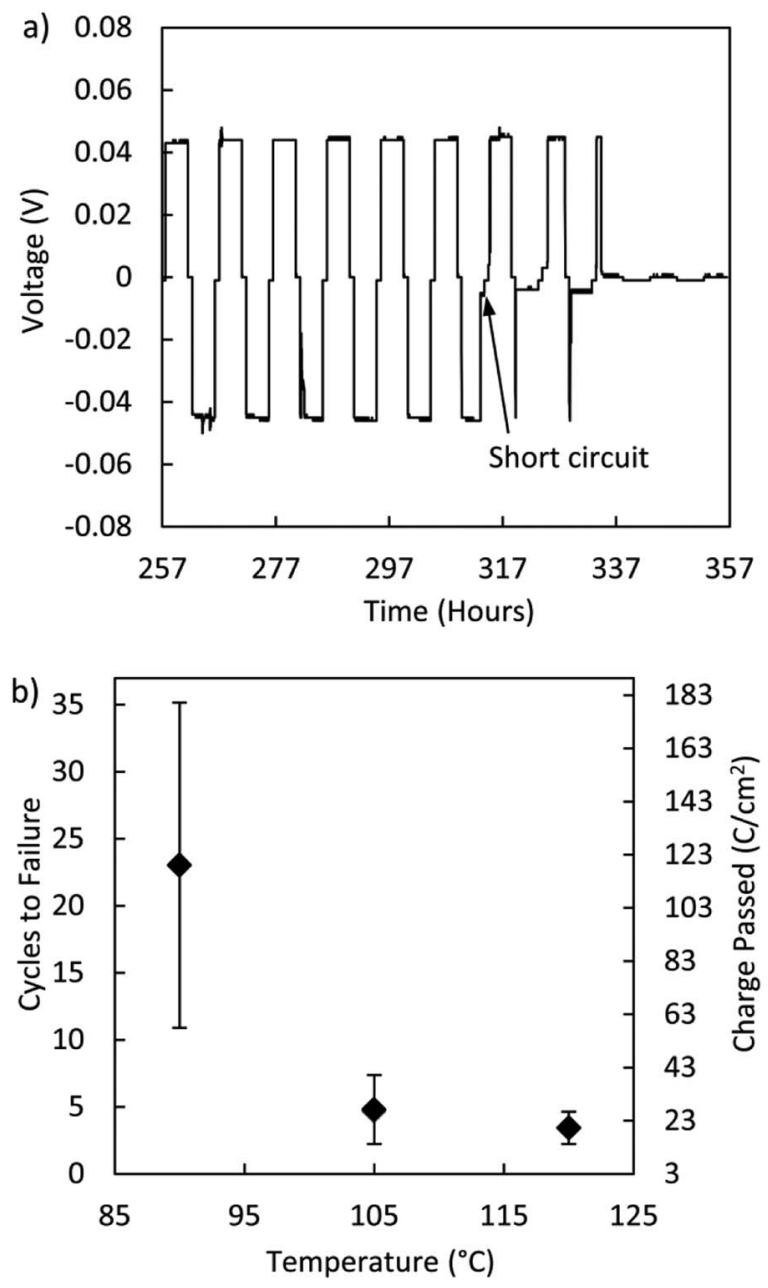

Figure 2. (a) Typical voltage versus time profile of a galvanostatically cycled symmetric cell, showing the last few cycles before cell shorting due to dendrite growth. (b) Average number of cycles to failure at 90,105 and $120^{\circ} \mathrm{C}$. Conditioning cycles are not included. The right ordinate converts cycles to charge density passed, including charge passed during conditioning cycles $\left(2.88 \mathrm{C} / \mathrm{cm}^{2}\right)$.

\section{Results and Discussion}

Figure 2a shows typical voltage versus time data obtained from our symmetric lithium-polymer-lithium cells. Cells were cycled galvanostatically at a constant current density of $0.175 \mathrm{~mA} / \mathrm{cm}^{2}$, with 45 min rest periods between switches in current direction. For the cell in the figure, at times before $257 \mathrm{~h}$, the voltage response is featureless, with values varying from 0.045 to $-0.045 \mathrm{~V}$. The small spikes seen in the first and second cycle in Figure $2 \mathrm{a}$ were observed throughout the cycling experiments, and may be due to unavoidable temperature fluctuations in the oven or unsteady processes within the cell. Deviations from steady cycling behavior are clearly visible at $\mathrm{t}=313$ $\mathrm{h}$, where a sharp increase in voltage to $-0.006 \mathrm{~V}$ is seen in spite of the imposition of a current density of $-0.175 \mathrm{~mA} / \mathrm{cm}^{2}$. We take this - the first time a sudden change of voltage response greater than $50 \%$ of the steady-state value was recorded and observed to persist for the remainder of the half cycle - as the signature of cell shorting. Cells sometimes recovered from this short circuit during subsequent cycles, as seen in Figure 2a, but generally failed permanently shortly thereafter. Similar cycling profiles were obtained at 105 and $120^{\circ} \mathrm{C}$.

The total number of cycles to failure was counted as full cycles including the cycle where the voltage drop signifying a short was seen, but not including the first five conditioning cycles described in the Experimental Section. A minimum of ten cells were cycled at each temperature. Average values of the total number of cycles before failure were calculated for each temperature and the results are plotted in Figure 2b. All error bars shown in this study reflect the standard deviation of the data. The figure also converts this cycle number to amount of charge passed, including charge passed during the conditioning cycles $\left(2.88 \mathrm{C} / \mathrm{cm}^{2}\right)$, before failure - see the right-hand ordinate of the plot. The large variation in cell life-time, especially at $90^{\circ} \mathrm{C}$, is probably due to the statistical nature of dendrite initiation and growth. We will show below that failed cells contained a wide variety of dendritic structures. Other factors such as imperfect control over electrolyte film quality, pressure applied during assembly, and impurities in the lithium foil may also contribute to the observed variance. In spite of the scatter in the data, it can be seen that cell lifetime decreases sharply as the cycling temperature is raised to $105^{\circ} \mathrm{C}$. Average life-time decreased from 23 cycles at $90^{\circ} \mathrm{C}$ to 4.7 cycles at $105^{\circ} \mathrm{C}$, a difference that is well outside experimental uncertainty. A further slight decrease in life-time to 4.0 cycles was observed when the cycling temperature was increased to $120^{\circ} \mathrm{C}$. One might conclude that the ability of SEO electrolytes to resist dendrite growth is lost abruptly at temperatures above $90^{\circ} \mathrm{C}$.

The nature of dendrite shorts that led to cell failure was established by X-ray microtomography. Typical digital cross-sections of reconstructed tomography images of electrolyte-spanning dendrites obtained at 90,105 and $120^{\circ} \mathrm{C}$ are shown in Figures $3 \mathrm{a}, 3 \mathrm{~b}$, and $3 \mathrm{c}$. Three-dimensional volume renderings of these dendrites are shown in Figures $3 \mathrm{~d}, 3 \mathrm{e}$, and $3 \mathrm{f}$. At $90^{\circ} \mathrm{C}$, a large fraction of the dendritic structure is contained within the electrode (Figures $3 \mathrm{a}$ and $3 \mathrm{~d}$ ). In addition, the dendrite is a finely-divided composite, with 5-20 $\mu \mathrm{m}$-wide dark globules of lithium metal surrounded by bright regions, composed of the SEO copolymer, LiTFSI and, perhaps, other organic compounds found in the SEI layer. In contrast, at $105^{\circ} \mathrm{C}$, a large fraction of the dendrite is contained within the electrolyte (Figures $3 \mathrm{~b}$ and $3 \mathrm{e}$ ). The lithium-rich regions in the dendrite are bulbous and much larger at $105^{\circ} \mathrm{C}$ relative to $90^{\circ} \mathrm{C}$, with correspondingly fewer inclusions of the polymer electrolyte. The dendrite at $120^{\circ} \mathrm{C}$ (Figures $3 \mathrm{c}$ and $3 \mathrm{f}$ ) shows elongated lithium structures in the direction of the applied current that differ qualitatively from the roughly spherical nodules seen at 90 and $105^{\circ} \mathrm{C}$. As was the case at $105^{\circ} \mathrm{C}$, most of the dendrite at $120^{\circ} \mathrm{C}$ resides within the electrolyte. The polygonal structure in the bottom lithium electrode in Figure 3c is a crystalline impurity in the electrode. The role of crystalline impurities in the lithium metal anodes is discussed in reference 13 .

In typical cells that were cycled at 90 and $105^{\circ} \mathrm{C}$, a wide variety of dendritic structures were observed. Most of them were not electrolytespanning, and examples of such structures are given in Figure 1. Since we punch out only a small fraction of the shorted cell for X-ray microtomography, electrolyte-spanning dendrites were not present in all samples imaged. At $120^{\circ} \mathrm{C}$, only a single dendritic structure was found in the 8 cells that were imaged. The remainder of the sample volumes contained no dendritic structures.

In Figure $4 \mathrm{a}$ we plot the average number of dendrites per unit surface area, calculated by dividing the total number of dendrites observed by the total electrode-electrolyte interfacial area analyzed at each temperature, as a function of cycling temperature. The average number of dendrites per unit surface area decreased from $1.1 \mathrm{~mm}^{-2}$ at $90^{\circ} \mathrm{C}$ to $0.4 \mathrm{~mm}^{-2}$ at $105^{\circ} \mathrm{C}$. This change in temperature resulted in a decrease in cell life-time by a factor of 4.9 while the average number of dendrites per unit electrode surface area decreased by a factor of only 2.8. It is unclear whether this corresponds to faster dendrite nucleation at higher temperature, since it is plausible that dendrite nucleation is nonlinear with time and amount of charge passed. The average number of dendrites per unit surface area at $120^{\circ} \mathrm{C}$ was $0.008 \mathrm{~mm}^{-2}$, a value significantly smaller than that obtained at lower temperatures. The reason for this dendrite scarcity, especially as compared to cells cycled at $105^{\circ} \mathrm{C}$, is unclear and cannot be explained by the slight decrease in cell life-time. The factors that govern this nucleation rate could include changes in surface and concentration overpotential, ${ }^{56}$ and SEI layer with temperature. Further work is required to quantify 

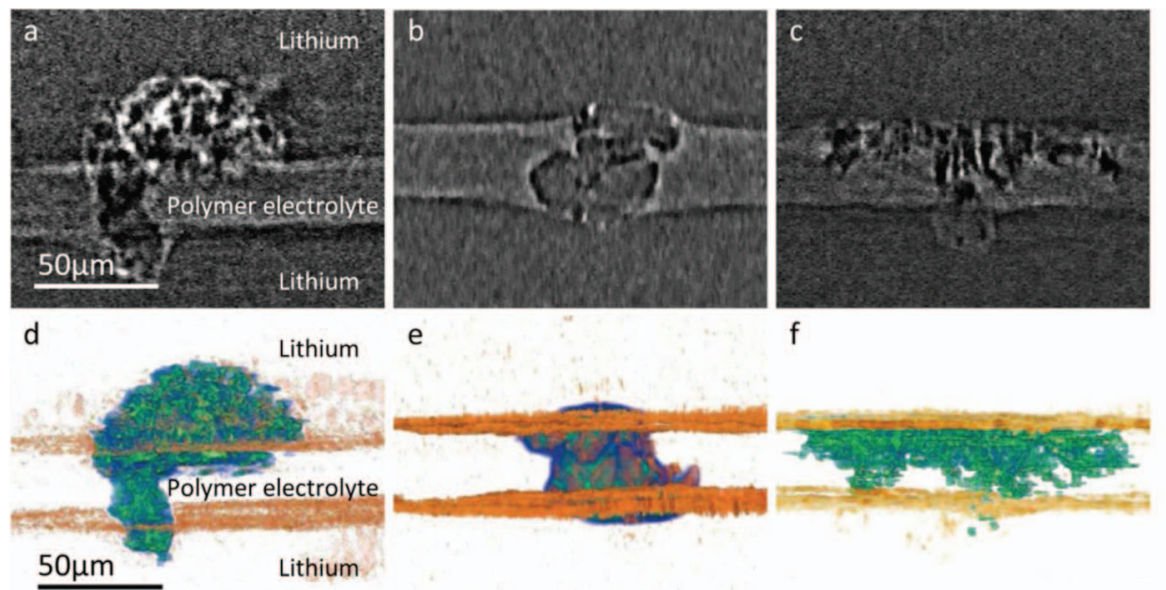

f

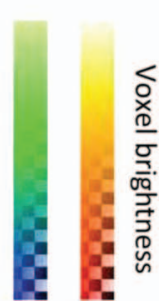

Figure 3. X-ray tomography images of dendrites present in cycled symmetric lithium cells. A typical electrolyte-spanning dendrite is shown for a cell cycled at (a) 90 , (b) 105 and (c) $120^{\circ} \mathrm{C}$. (d-f) 3D volume renderings of the dendrites in (a-c) more clearly show the large difference in percentage of the dendrite located within the lithium electrodes (above top orange line and below bottom orange line) versus in the electrolyte (between the orange lines). Cycling temperatures were (d) 90 , (e) 105 , and (f) $120^{\circ} \mathrm{C}$. Again, the color bars show relative voxel brightness values but exact values do not directly correspond between any of the images shown.

these effects in low transference number electrolytes such as SEO. The influence on dendrite growth of the SEI layer is ignored in the current analysis.
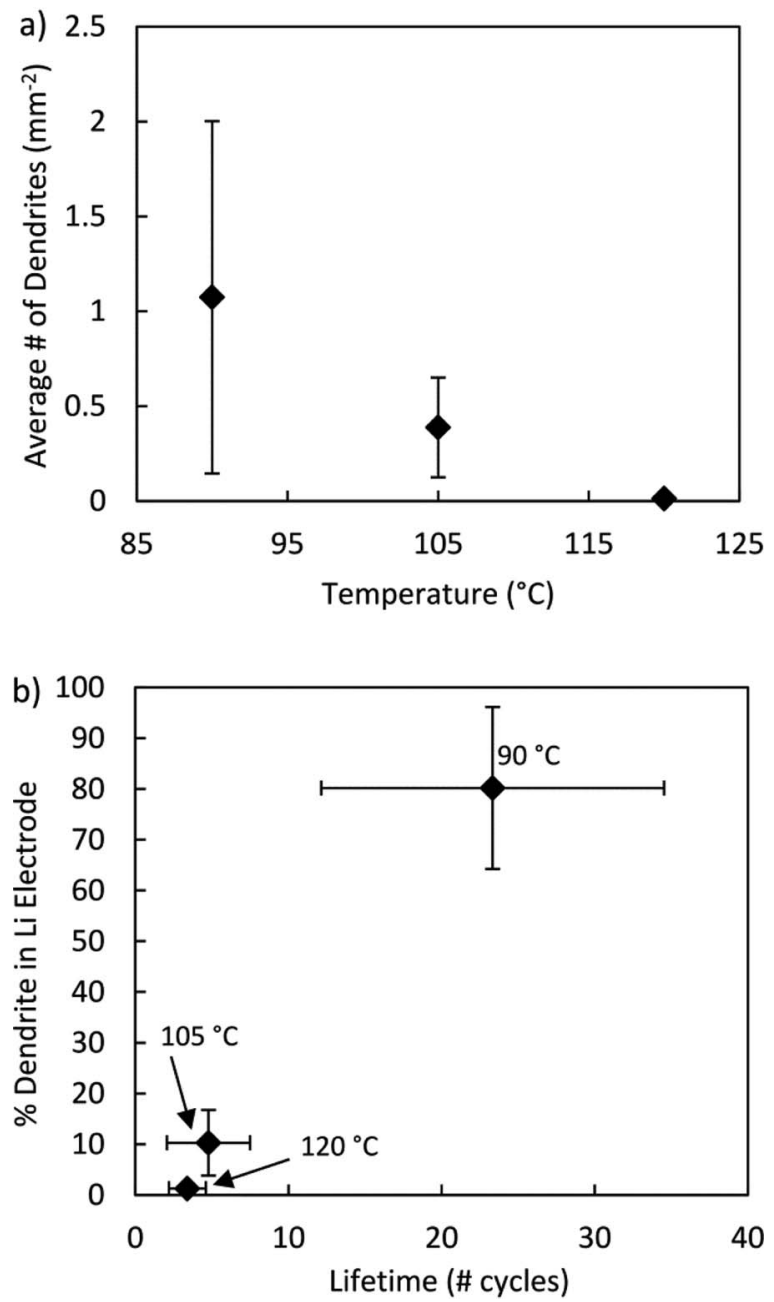

Figure 4. (a) Average number of dendrites seen per unit area as a function of cycling temperature. (b) Average percentage of dendrite volume located in lithium electrode versus cell life-time for each cycling temperature.
Quantitative results for the average percent of dendrite residing in the lithium electrodes were also calculated from the X-ray tomograms. These percentages were then averaged over several independent dendritic structures at each temperature $\left(16\right.$ at $90^{\circ} \mathrm{C}, 10$ at $105^{\circ} \mathrm{C}$, and 1 at $120^{\circ} \mathrm{C}$ ). At $90^{\circ} \mathrm{C}$, an average of $80 \%$ of each dendrite resided within the electrode. In contrast, at $105^{\circ} \mathrm{C}$, only $10 \%$ of each dendrite resided in the electrode, while at $120^{\circ} \mathrm{C}$ this fraction reduces to $1 \%$. Percent of dendrite in the electrode is plotted as a function of cell life-time in Figure 4b. Dendritic structures grow within the electrode in cells with long cycle life; in contrast, dendritic structures grow within the electrolyte in cells with short cycle life.

The average properties of dendrites reported in Figure 4 obscure the broad range of dendritic structures that were observed in our cells. To clarify this, we plot the dendrite height in the electrolyte versus total dendrite volume for all dendrites analyzed at each temperature in Figure 5. Dendrite height was measured as the perpendicular distance from the intersection of the dendrite with the electrode-electrolyte interface to the tip of the dendrite in the electrolyte. In order for a

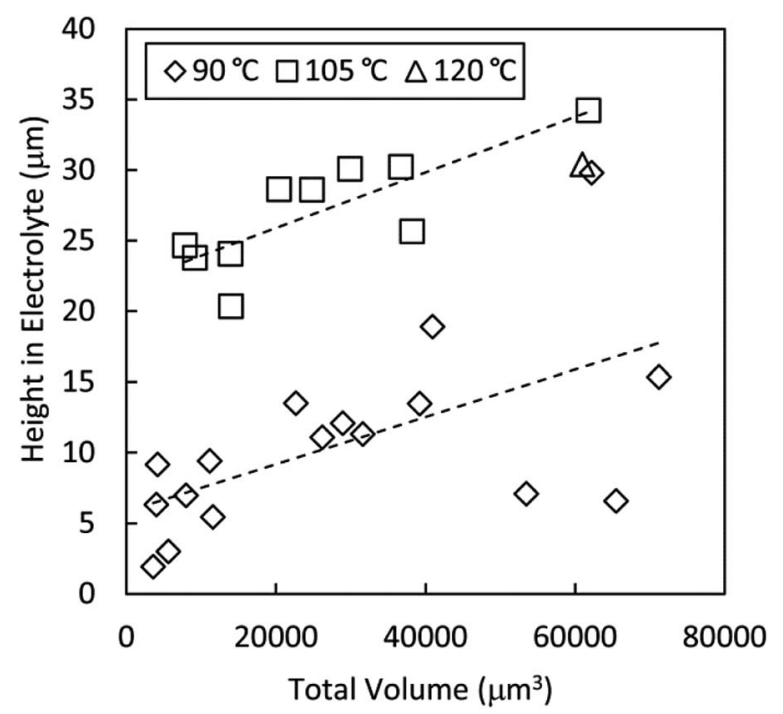

Figure 5. Height of dendrite protruding into the SEO electrolyte, in $\mu \mathrm{m}$, plotted against total dendrite volume, in $\mu \mathrm{m}^{3}$, for dendrites imaged in shorted cells cycled at 90,105 and $120^{\circ} \mathrm{C}$. Linear fits to the 90 and $105^{\circ} \mathrm{C}$ data are shown as dashed lines. 
Table II. Average symmetric cell properties at each cycling temperature.

\begin{tabular}{llllll} 
Temperature $\left({ }^{\circ} \mathrm{C}\right)$ & $\Delta V^{\mathrm{a}}(\mathrm{V})$ & $\sigma^{\mathrm{b}}(\mathrm{S} / \mathrm{cm})$ & $R_{\text {int }}{ }^{\mathrm{c}}\left(\Omega \mathrm{cm}^{2}\right)$ & $R^{\mathrm{d}}\left(\Omega \mathrm{cm}^{2}\right)$ & $\Delta V / \Delta V_{90}{ }^{\mathrm{e}}$ \\
\hline 90 & 0.056 & $3.3 \times 10^{-4}$ & 136 & 144 & 1 \\
105 & 0.021 & $4.5 \times 10^{-4}$ & 42.4 & 48.3 & 1 \\
120 & 0.009 & $6.1 \times 10^{-4}$ & 15.5 & 19.6 & 0.38 \\
& & & 0.33 & 0.15
\end{tabular}

${ }^{\mathrm{a}} \Delta V$ is the average steady-state voltage,

$\mathrm{b}^{\mathrm{b}}$istheconductivityofourelectrolyte,

${ }^{\mathrm{c}} R_{\text {int }}$ is the interfacial impedance,

${ }^{\mathrm{d}} R$ is the total cell impedance, and

${ }^{\mathrm{e}} \Delta V / \Delta V_{90}$ and $R / R_{90}$ are the ratio of $\Delta V$ and $R$ at the temperature of interest to that at $90^{\circ} \mathrm{C}$.

dendrite to short the cell, it must grow fully across the electrolyte; dendrite height in the electrolyte is therefore a metric for how close a dendrite is to causing cell failure. The data in Figure 5 indicates that this dendrite height is invariably smaller in a cell cycled at $90^{\circ} \mathrm{C}$ than in a cell cycled at $105^{\circ} \mathrm{C}$ across the wide range of dendrite sizes observed. Dendrites of a given volume in cells cycled at $105^{\circ} \mathrm{C}$ are about $15 \mu \mathrm{m}$ taller than those in cells cycled at $90^{\circ} \mathrm{C}$. They are thus more likely to reach the other electrode and short the cell at $105^{\circ} \mathrm{C}$.

The average steady-state voltage during cycling, $\Delta V$, was $0.056 \mathrm{~V}$ at $90^{\circ} \mathrm{C}, 0.021 \mathrm{~V}$ at $105^{\circ} \mathrm{C}$ and $0.009 \mathrm{~V}$ at $120^{\circ} \mathrm{C}$. The ranges of steady-state voltages during cycling were 0.026 to $0.133 \mathrm{~V}$ at $90^{\circ} \mathrm{C}$ (see example in Figure 2a), 0.013 to $0.03 \mathrm{~V}$ at $105^{\circ} \mathrm{C}$ and 0.0058 to $0.0115 \mathrm{~V}$ at $120^{\circ} \mathrm{C}$. We attribute the decrease in deltaV with increasing temperature to the decrease in resistance between the lithium electrodes as temperature increases. This is established in Table II, where we list the temperature-dependent values of $\Delta V$, the conductivity of our electrolyte, $\sigma$, interfacial impedance, $R_{\text {int }}$, and total cell impedance, $R$. These values were derived from ac impedance measurements made on all of the cells prior to cycling. Also given in Table II are $\Delta V / \Delta V_{90}$ and $R / R_{90}$, the ratio of $\Delta V$ and $R$ at the temperature of interest to that at $90^{\circ} \mathrm{C}$. Similarity of $R / R_{90}$ and $\Delta V / \Delta V_{90}$ values suggests that observations as a function of temperature are not due to differences in the rate of side reactions or changes in the electrochemical stability of the electrolyte; both factors would result in noticeable increases in interfacial impedance.

Models of dendrite growth suggest that both electrochemical and mechanical properties are important in determining cell performance..$^{33,57,58}$ As established above, our cell cycling data suggest no unexpected major differences in interfacial impedance as a function of temperature. It is therefore appropriate to examine the temperature dependency of the mechanical properties of our polymer electrolyte. In Figures 6a and 6b we show the frequency $(\omega)$ dependency of the storage $\left(G^{\prime}\right)$ and loss $\left(G^{\prime \prime}\right)$ moduli of SEO as a function of increasing temperature. Current models for dendrite growth assume the presence of an ideal elastic solid electrolyte. ${ }^{33}$ Such a material would exhibit a $\omega$-insensitive $G^{\prime}$ and negligible $G^{\prime \prime}\left(\ll G^{\prime}\right)$. At low temperature $\left(90^{\circ} \mathrm{C}\right)$, the SEO copolymer is essentially elastic, reflecting the glassy rigidity of the PS domains. In contrast, at higher temperatures the magnitudes of $G^{\prime}$ and $G^{\prime \prime}$ vary with $\omega$ and are comparable over wide ranges of $\omega$ and temperature. The softening of the SEO, seen as the temperature is increased from 97 to $105^{\circ} \mathrm{C}$, signifies the glass-to-rubber transition of the PS microphase; the $T_{\mathrm{g}}$ of the PS microphase in neat SEO and in the LiTFSI/SEO electrolyte, determined by differential scanning calorimetry, was 108 and $107^{\circ} \mathrm{C}$, respectively. At these higher temperatures, the material becomes a viscoelastic solid, as seen by the low- $\omega$ plateau of $G^{\prime}$. This feature could result from the elastic resistance to deformation arising from either the inter-domain interfaces or inter-grain defects.

Our observation that the SEO copolymer is a complex viscoelastic material is consistent with a large body of work on the rheological properties of block copolymers. ${ }^{59-63}$ The standard approach for elucidating the $\omega$-dependency of $G^{\prime}$ and $G^{\prime \prime}$ of polymers over windows of $\omega$ that are not experimentally accessible is time-temperature superposition. ${ }^{64,65}$ Application of this principle to the data in Figure 6 is shown in Figure 7, where the abscissa is $\log \left(\omega a_{\mathrm{T}}\right)$, where
$a_{\mathrm{T}}$ is the shift factor. The reference temperature, $T_{\mathrm{r}}$, used for the timetemperature superposition is $90^{\circ} \mathrm{C}$, i.e. $a_{\mathrm{T}}=1$ at $90^{\circ} \mathrm{C}$. The $G^{\prime}$ and $G^{\prime \prime}$ data are multiplied by a minor correction factor for entropy elasticity, $b_{\mathrm{T}}=T_{\mathrm{r}} / T$ (in $\mathrm{K}$ ). The shift factors used to obtain Figure $7 \mathrm{a}$ were chosen manually to superpose the high- $\omega$ part of the $G^{\prime}$ versus $\omega$ data in Figure 6a onto a single master curve.$^{60,63}$ Figure $7 \mathrm{~b}$ shows shifted $G^{\prime \prime}$ versus $\log \left(\omega a_{\mathrm{T}}\right)$ using the same shift factors as in Figure 7a. The temperature dependency of $a_{\mathrm{T}}$ is shown in Figure 7c. The shift works reasonably well for both $G^{\prime}$ and $G^{\prime \prime}$ data at high temperature $\left(\geq 105^{\circ} \mathrm{C}\right)$, though detectable deviations remain. Such deviations are often observed in nanostructured block copolymers comprising domains that present different activation energies due to differences in $T_{\mathrm{g}} .{ }^{60,63,66,67}$ The success of time-temperature superposition at high
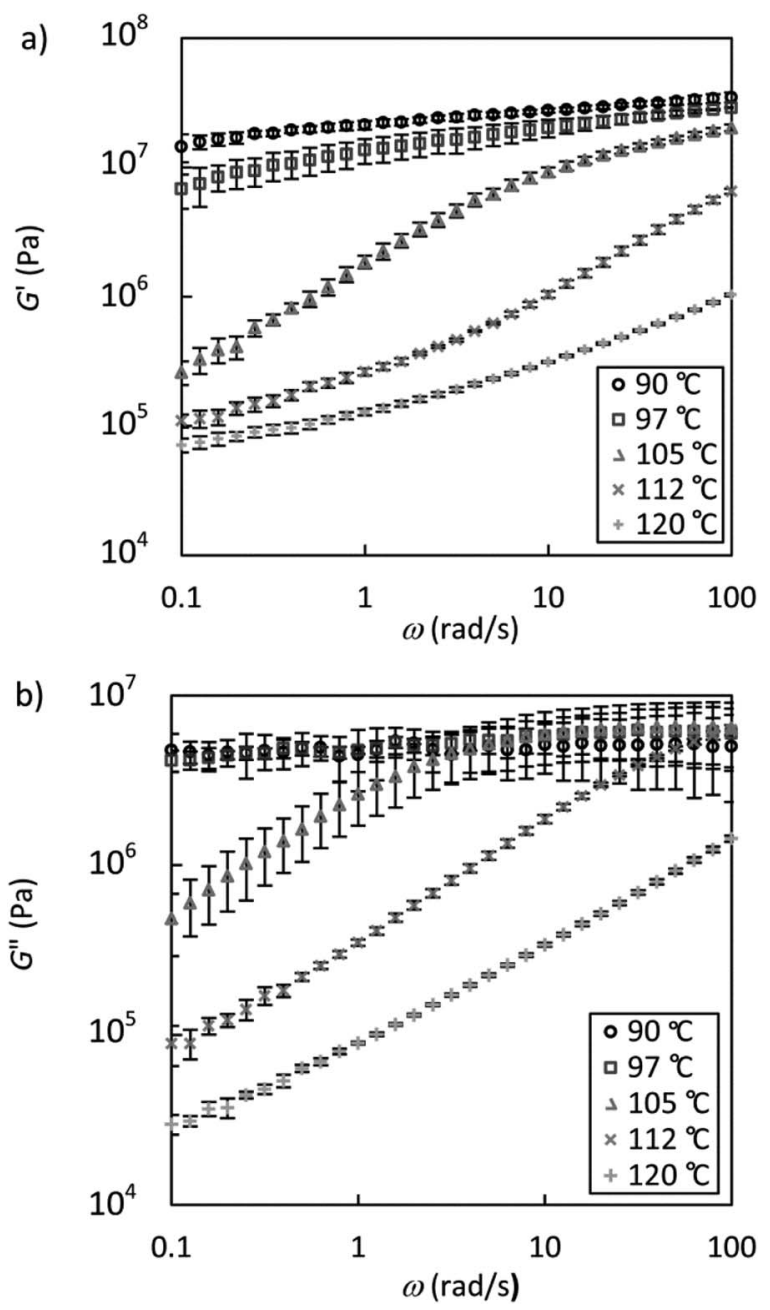

Figure 6. Frequency $(\omega)$ dependency of (a) storage $\left(G^{\prime}\right)$ and (b) loss $\left(G^{\prime \prime}\right)$ moduli measured at $90,97,105,112$ and $120^{\circ} \mathrm{C}$. 

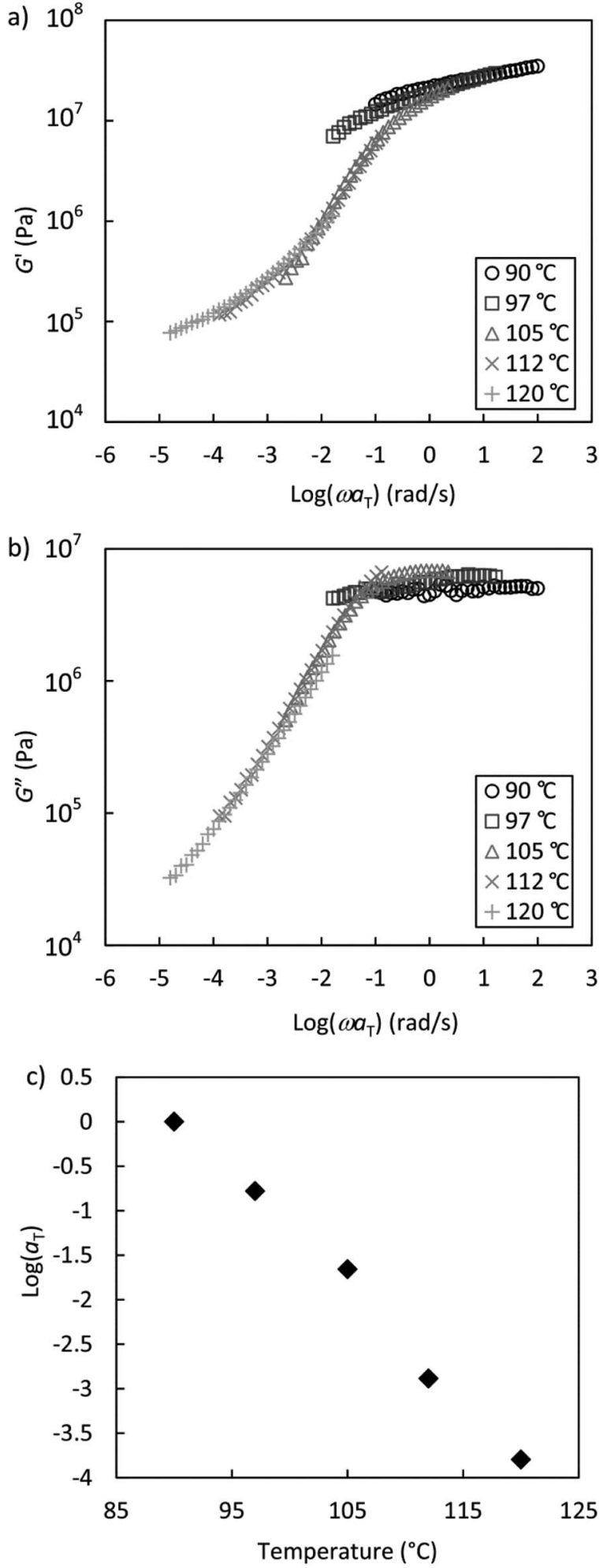

Figure 7. Time-temperature superposition of (a) $G^{\prime}$ and (b) $G^{\prime \prime}$ of the data presented in Figure 6, with $\mathrm{T}_{\mathrm{r}}=90^{\circ} \mathrm{C}$. The same shift factors are used for both master curves. (c) Shift factors, $\log \left(a_{\mathrm{T}}\right)$, plotted as a function of temperature.

temperatures may have resulted from temperature-insensitivity of the viscoelastic response of the inter-domain interfaces and inter-grain defects, ${ }^{61}$ or from a decrease of the viscoelastic contrast between PS and PEO.

In Figure 8 we show the effect of the viscoelastic properties of the SEO electrolyte on dendrite growth. In this figure, we plot the

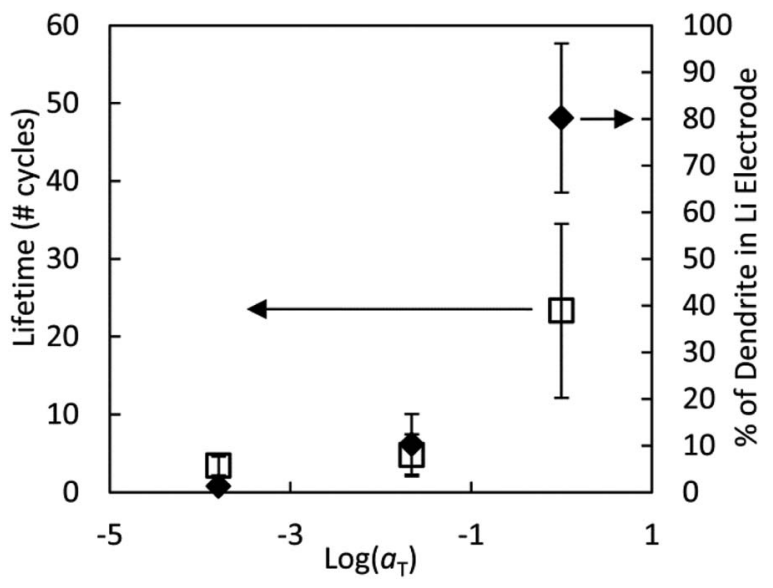

Figure 8. Average cell life-time (squares) and average percentage of dendrite volume located in lithium electrode (diamonds) plotted versus shift factor, $\log \left(a_{\mathrm{T}}\right)$, for data obtained at 90,105 and $120^{\circ} \mathrm{C}$.

cell life-time, as obtained from the galvanostatic cycling data, and the percent of dendrite in the electrode, as obtained by X-ray microtomography, as a function of $\log \left(a_{\mathrm{T}}\right)$. It is evident that when $a_{\mathrm{T}}=1$, dendrites reside primarily in the electrode. This may be taken as a signature of the electrolyte pushing back on the dendrite as it grows which, in turn, results in longer cycle life. The rigidity sustained by the glassy PS domain at this temperature is the main factor contributing to the mechanical resistance of the SEO. At lower values of $a_{\mathrm{T}}$, the inter-domain interfaces and inter-grain defects are the dominant contributions to resistance of dendrite growth. As seen from the significant decrease in cell life-time and percent dendrite in the electrode, this resistance is much weaker compared to that arising from glassy domains. The local direction of dendrite growth is an important issue that the present experiments do not address directly. The presence of roughly spherical globular substructures at 90 and $105^{\circ} \mathrm{C}$ suggests a lack of preference for a particular growth direction. Perhaps the characteristic dimensions of growing dendritic structures are large enough to average over several block copolymer domains that are randomly oriented in our samples. In contrast, the presence of elongated substructures in the direction of the electric field at $120^{\circ} \mathrm{C}$ indicates a correlation between the direction of lithium migration and dendrite growth, which is consistent with a large body of literature on dendrite growth on metal surfaces against liquid electrolytes. ${ }^{49,55}$ It is evident that our SEO electrolyte, which resisted dendrite growth at $90^{\circ} \mathrm{C}$, is similar to conventional electrolytes at $120^{\circ} \mathrm{C}$.

A thorough analysis of dendrite growth into viscoelastic polymer electrolytes would require the development of a framework that couples the deformation induced by uneven electrochemical deposition near a dendrite with the viscous flow and shear and normal stresses that occur due to the finite values of $G^{\prime}$ and $G^{\prime \prime}$. If the growth of the dendrite excites a particular frequency, then dendrite growth would be dependent on the values of $G^{\prime}$ and $G^{\prime \prime}$ at that frequency. It is, however, likely that dendrite growth excites a range of frequencies. In the absence of knowledge of the relevant range of frequencies, the proposed approach of using shift factors to compare dendrite growth at various temperatures is, perhaps, a logical first step toward characterizing dendrite growth in complex viscoelastic media. Further work is required to address this important issue.

\section{Conclusions}

The relationship between temperature and dendrite growth in symmetric lithium/SEO electrolyte/lithium cells was studied by galvanostatic cycling and hard X-ray microtomography. A dramatic decrease in the amount of charge passed at cell failure was observed when cycling was conducted at 105 and $120^{\circ} \mathrm{C}$ as compared to cycling at $90^{\circ} \mathrm{C}$. The nature of lithium dendrites that caused cell failure was 
determined by X-ray microtomography. At $90^{\circ} \mathrm{C}$, a large portion of the dendritic structure resided within the lithium electrode, while at 105 and $120^{\circ} \mathrm{C}$ most of the dendrite was located within the electrolyte. An understanding of the reason for the shift in dendrite location with respect to the electrode-electrolyte interface was obtained by examining the rheological properties of the SEO copolymer. As the temperature was increased, both $G^{\prime}$ and $G^{\prime \prime}$ decreased significantly in the low frequency regime. Time-temperature superposition was employed to estimate $G^{\prime}$ and $G^{\prime \prime}$ over a wider range of frequencies than is experimentally feasible. Cycle life and the fraction of the dendritic structure located within the electrode were found to be sensitive functions of shift factors used to obtain time-temperature superposition.

\section{Acknowledgments}

We thank Jing Sun of the Lawrence Berkeley National Laboratory, for her help with the DSC sample preparation and measurements. Primary funding for the work was provided by the Electron Microscopy of Soft Matter Program from the Office of Science, Office of Basic Energy Sciences, Materials Sciences and Engineering Division of the U.S. Department of Energy under Contract No. DEAC02-05CH11231. The battery assembly portion of the project was supported by the BATT program from the Vehicle Technologies program, through the Office of Energy Efficiency and Renewable Energy under U.S. DOE Contract DE-AC02-05CH11231. Hard X-ray microtomography experiments were performed at the Advanced Light Source which is supported by the Director, Office of Science, Office of Basic Energy Sciences, of the U.S. Department of Energy under Contract No. DE-AC02-05CH11231. Katherine J. Harry was supported by a National Science Foundation Graduate Research Fellowship.

\section{References}

1. J. M. Tarascon and M. Armand, Nature, 414, 359 (2001).

2. R. Rauh, K. Abraham, G. Pearson, J. Surprenant, and S. Brummer, J. Electrochem. Soc, 126, 523 (1979).

3. P. G. Bruce, L. J. Hardwick, and K. M. Abraham, MRS Bull, 36, 506 (2011).

4. P. G. Bruce, S. A. Freunberger, L. J. Hardwick, and J. Tarascon, Nature Materials, 11, 19 (2012).

5. S. Cheon, K. Ko, J. Cho, S. Kim, E. Chin, and H. Kim, J. Electrochem. Soc., 150 , A796 (2003).

6. K. Abraham and Z. Jiang, J. Electrochem. Soc., 143, 1 (1996).

7. T. Ogasawara, A. Debart, M. Holzapfel, P. Novak, and P. Bruce, J. Am. Chem. Soc. 128, 1390 (2006)

8. H. Kitaura and H. Zhou, Energy \& Environmental Science, 5, 9077 (2012).

9. K. G. Gallagher, S. Goebel, T. Greszler, M. Mathias, W. Oelerich, D. Eroglu, and V. Srinivasan, Energy \& Environmental Science, 7, 1555 (2014).

10. N. P. Balsara and J. Newman, J. Chem. Educ., 90, 446 (2013).

11. R. Bhattacharyya, B. Key, H. Chen, A. S. Best, A. F. Hollenkamp, and C. P. Grey, Nature Materials, 9, 504 (2010).

12. S. Chandrashekar, N. M. Trease, H. J. Chang, L. Du, C. P. Grey, and A. Jerschow, Nature Materials, 11, 311 (2012).

13. K. J. Harry, D. T. Hallinan, D. Y. Parkinson, A. A. MacDowell, and N. P. Balsara, Nature Materials, 13, 69 (2014).

14. S. Tobishima and J. Yamaki, J. Power Sources, 81-82, 882 (1999),

15. H. Honbo, K. Takei, Y. Ishii, and T. Nishida, J. Power Sources, 189, 337 (2009).

16. J. E. Weston and B. C. H. Steele, Solid State Ionics, 7, 75 (1982).

17. K. Abraham and M. Alamgir, J. Electrochem. Soc., 137, 1657 (1990).

18. J. B. Bates, N. J. Dudney, G. R. Gruzalski, R. A. Zuhr, A. Choudhury, C. F. Luck, and J. D. Robertson, J. Power Sources, 43, 103 (1993).

19. E. Eweka, J. R. Owen, and A. Ritchie, J. Power Sources, 65, 247 (1997)

20. G. Appetecchi, F. Croce, L. Persi, F. Ronci, and B. Scrosati, Electrochim. Acta, 45, 1481 (2000).

21. Y. Lu, S. S. Moganty, J. L. Schaefer, and L. A. Archer, J. Mater. Chem., 22, 4066 (2012)

22. Q. Lu, J. Fang, J. Yang, G. Yan, S. Liu, and J. Wang, J. Membr. Sci., 425, 105 (2013).
23. D. Fenton, J. Parker, and P. Wright, Polymer, 14, 589 (1973).

24. M. B. Armand, J. M. Chabagno, and M. J. Duclot, Fast Ion Transport in Solids. Electrodes and Electrolytes, 131 (1979).

25. B. L. Papke, M. A. Ratner, and D. F. Shriver, Journal of Physics and Chemistry of Solids, 42, 493 (1981).

26. J. E. Weston and B. C. H. Steele, Solid State Ionics, 2, 347 (1981).

27. M. Armand, Solid State Ionics, 9-10, 745 (1983).

28. M. Gauthier, D. Fauteux, G. Vassort, A. Belanger, M. Duval, P. Ricoux, J. M. Chabagno, D. Muller, P. Rigaud, M. B. Armand, and D. Deroo, J. Electrochem. Soc., 132, 1333 (1985)

29. C. Brissot, M. Rosso, and J. N. Chazalviel, Proceedings of the Second International Symposium on New Materials for Fuel-Cell and Modern Battery Systems II, 908-910 (1997).

30. M. Rosso, T. Gobron, C. Brissot, J. N. Chazalviel, and S. Lascaud, J. Power Sources, 97-8, 804 (2001).

31. C. Brissot, M. Rosso, J. N. Chazalviel, and S. Lascaud, Studies in Surface Science and Catalysis, 132, 947 (2001)

32. M. Dolle, L. Sannier, B. Beaudoin, M. Trentin, and J. Tarascon, Electrochemical and Solid State Letters, 5, A286 (2002).

33. C. Monroe and J. Newman, J. Electrochem. Soc., 152, A396 (2005).

34. S. Zhang, K. H. Lee, J. Sun, C. D. Frisbie, and T. P. Lodge, Macromolecules, 44, 8981 (2011).

35. S. Liu, N. Imanishi, T. Zhang, A. Hirano, Y. Takeda, O. Yamamoto, and J. Yang, J. Power Sources, 195, 6847 (2010).

36. S. Kim, K. Choi, S. Cho, E. Kil, and S. Lee, J. Mater. Chem. A, 1, 4949 (2013).

37. C. Berthier, W. Gorecki, M. Minier, M. Armand, J. Chabagno, and P. Rigaud, Solid State Ionics, 11, 91 (1983).

38. C. Wang, T. Sakai, O. Watanabe, K. Hirahara, and T. Nakanishi, J. Electrochem. Soc., 150, A1166 (2003).

39. M. Singh, O. Odusanya, G. M. Wilmes, H. B. Eitouni, E. D. Gomez, A. J. Patel, V. L. Chen, M. J. Park, P. Fragouli, H. Iatrou, N. Hadjichristidis, D. Cookson, and N. P. Balsara, Macromolecules, 40, 4578 (2007).

40. D. T. Hallinan, S. A. Mullin, G. M. Stone, and N. P. Balsara, J. Electrochem. Soc., 160, A464 (2013).

41. S. A. Mullin, Ph.D. Thesis, University of California, Berkeley (2011)

42. G. M. Stone, S. A. Mullin, A. A. Teran, D. T. Hallinan Jr., A. M. Minor, A. Hexemer, and N. P. Balsara, J. Electrochem. Soc., 159, A222 (2012).

43. J. Yamaki, S. Tobishima, K. Hayashi, and K. Keiichi Saito, Y. Nemoto and M. Arakawa, J. Power Sources, 74, 219 (1998).

44. M. S. Park, S. B. Ma, D. J. Lee, D. Im, S. Doo, and O. Yamamoto, Scientific Reports, 4, 3815 (2014).

45. O. Crowther and A. C. West, J. Electrochem. Soc., 155, A806 (2008)

46. C. Fringant, A. Tranchant, and R. Messina, Electrochim. Acta, 40, 513 (1995).

47. L. Gireaud, S. Grugeon, S. Laruelle, B. Yrieix, and J.-M. Tarascon, Electrochemistry Communications, 8, 1639 (2006).

48. K. Kanamura, S. Shiraishi, H. Tamura, and Z. Takehara, J. Electrochem. Soc., 141, 2379 (1994).

49. T. Tatsuma, M. Taguchi, and N. Oyama, Electrochim. Acta, 46, 1201 (2001).

50. A. A. Teran and N. P. Balsara, J Phys Chem B, 118, 4 (2014).

51. A. Panday, S. Mullin, E. D. Gomez, N. Wanakule, V. L. Chen, A. Hexemer, J. Pople, and N. P. Balsara, Macromolecules, 42, 4632 (2009).

52. A. A. MacDowell, D. Y. Parkinson, A. Haboub, E. Schaible, J. R. Nasiatka, C. A. Yee, J. R. Jameson, J. B. Ajo-Franklin, C. R. Brodersen, and A. J. McElrone, Developments in X-Ray Tomography Viii, 8506, UNSP 850618 (2012).

53. M. Ebner, F. Marone, M. Stampanoni, and V. Wood, Science, 342, 716 (2013).

54. F. Maia, A. MacDowell, S. Marchesini, H. A. Padmore, D. Y. Parkinson, J. Pien, A. Schirotzek, and C. Yang, Image Reconstruction from Incomplete Data Vi, 7800, $78000 \mathrm{~F}(2010)$.

55. C. M. Lopez, J. T. Vaughey, and D. W. Dees, J. Electrochem. Soc., 156, A726 (2009)

56. J. Barton and J. Bockris, Proceedings of the Royal Society of London Series AMathematical and Physical Sciences, 268, 485 (1962).

57. C. Monroe and J. Newman, J. Electrochem. Soc., 150, A1377 (2003)

58. C. Monroe and J. Newman, J. Electrochem. Soc., 151, A880 (2004).

59. D. Fesko and N. Tschoegl, Journal of Polymer Science Part C-Polymer Symposium, 51 (1971)

60. R. Cohen and N. Tschoegl, Transactions of the Society of Rheology, 20, 153 (1976)

61. J. Rosedale and F. Bates, Macromolecules, 23, 2329 (1990).

62. R. Colby, Current Opinion in Colloid \& Interface Science, 1, 454 (1996).

63. A. J. Patel, S. Mochrie, S. Narayanan, A. Sandy, H. Watanabe, and N. P. Balsara, Macromolecules, 43, 1515 (2010)

64. J. Ferry, J. Am. Chem. Soc., 72, 3746 (1950).

65. J. Ferry, Viscoelastic Properties of Polymers, Wiley, New York, (1980)

66. C. K. Lim, R. E. Cohen, and N. W. Tschoegl, Advances in Chemistry Series, 397 (1971).

67. D. G. Fesko and N. W. Tschoegl, Int. J. Polym. Mater, 3, 51 (1974). 